\title{
Digital Design of Visual Recognition System for Enterprise
}

\author{
WU Lei ${ }^{1, a}$ \\ ${ }^{1}$ Wuhan Textile University College of Art and Design, Wuhan 430073,China \\ awulei027@163.com
}

Keywords: Visual recognition systems; Image recognition; Digital design; Culture and creativity industries

\begin{abstract}
With the development of information technology, digital graphics are widely into our life. Whether learning, convey or commercial use, digital graphics monopoly on almost all the multimedia media in the modern art design. Sound art, visual arts and interactive art that developed along with the development of modern art design and based on it has also gradually grown up. It is in such a background, digital enterprise image design system quietly born. Because of its particularity, artistic visual communication design and new perspective of technical creativity, we informally defined them as digital image visual identification system.
\end{abstract}

\section{Visual recognition system}

\section{Visual identification system overview}

Visual identification system is also referred to as VI, which use unified and systematic visual symbol system to convey the image of the enterprise. As one of the most infectious and part of the propagation force, enterprise recognition system, VI converts the visual content into static visual identification symbols. Under the guidance of business enterprise principle of management, the VI inject enterprise inner temperament, enterprise culture, management objective model in its design products by using the method of visual communication, convey to the consumer through some media. Ultimate aim is to make the enterprise internal and consumers from all walks of life to produce consistent identity and values of the firm. VI is static identification symbols, in today's rapid development of multimedia technology, seem a bit less.

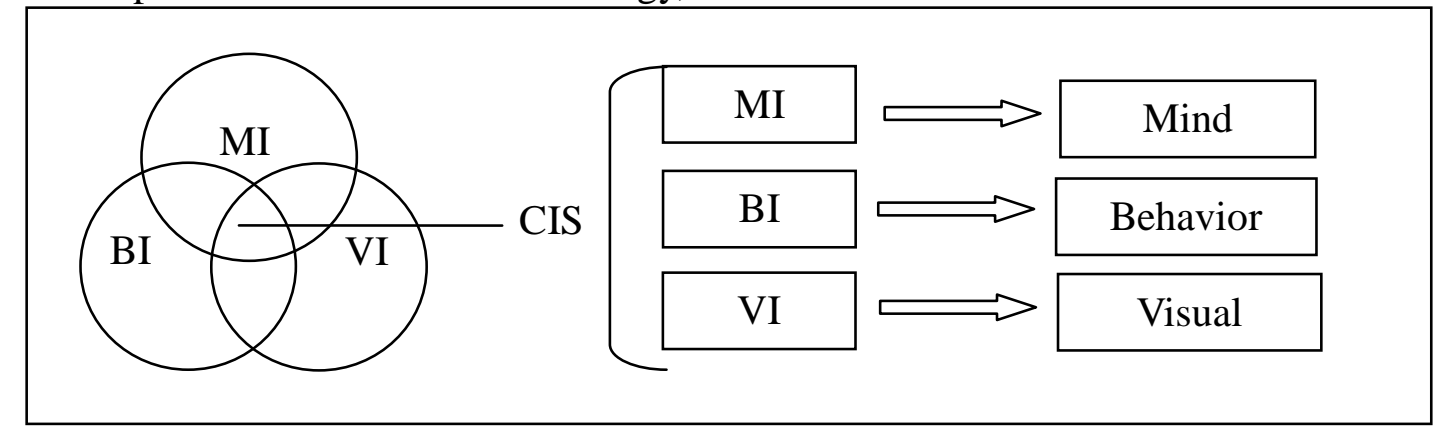

Figure 1. Complete CIS system formed by MI, BI, VI

\section{Design principle of visual recognition system}

\section{1) Market-oriented}

Market-oriented principle refers to the VI design and import must have a market research and analysis of the material as a support, otherwise design out of the market actual situation are just castles in the air does not conform to the real need. Therefore, only when the design set up scientific idea of the market principle accurately, can make a work created by accepted by market. Market-oriented embodied in three aspects: first, in line with the industry characteristics; second, meeting the needs of the target audience aesthetic; three, in line with the market environment.

\section{2) Unity}

Make the enterprise image consistency and consistency in the process of external communication is an important principle of VI design, so you need to use the perfect vision enables 
the spread on a variety of media to maintain unity. Using the unified language to convey all kinds of design of this brand, show a visual image of the integration. [1] So it can strengthen enterprise image, accelerate information transmission, and leave deep impression to the audience in a certain extent.

\section{3) Differences}

Today's society develops in a diversified way. The reason why companies are able to get consumer recognition mainly is they captures the difference principle of this design in the process of brand communication. Diversity embodies in different industries, according to the psychological characteristics of consumers; enterprises of different industries will have obvious industry characteristics, therefore, the design need to highlight the industry characteristics and to show the particularity of the enterprise at the same time, easy to distinguish with other enterprises. In order to clearly show the corporate image features, personalized processes can be conducted from four aspects: personalize visual concept; personalize visual elements; personalize color; personalize the application system development.

\section{4) Practicality}

VI design practical is also called the effectiveness. It refers to that the VI design effectively used in the actual environment is not dress up, but to solve the enterprise image to communicate the problem, so you need to have strong practicality in each design.

\section{Common application software}

In the digital information age, the computer has become a darling of the times, more and more widely permeated various fields of art and design, becoming one of the indispensable design tools for designers. But also cause severe shock for the traditional design method and means. [2]Of course, it also has impact on the design of corporate image design methods and means. But it is not hard to find that artistic creativity is the soul of software technology, software technology is a sign of artistic originality means. The key to design is being creative, but indispensable from the final visual effect and design method, process, means.

\section{CorelDraw}

CorelDraw is a software graphics and layout of the, which is widely used in logo design, logo, model drawing, illustration painting, typography, and color output, and many other fields. CorelDraw make designers can easily deal with all kinds of creative graphic design, document compatibility with leading position in the market with high quality of the work effect. From different logo and logo to the compelling marketing materials and pleasing Web graphics, you name it. CorelDraw are highly trusted by consumers and companies around the world, show the effect of the user's conception with professional perfect, and improve business efficiency.

CorelDraw's word processing and image input and output functions constitute the layout function. Word processing of it is by far the most excellent of all the software, it supports for the most part the image format of the input and output, almost unimpeded to exchange with other software sharing files, so most designers use the PC for design like directly lay in CorelDraw format, then output color separation.

\section{Illustrator}

Illustrator is professional vector drawing tools that ADOBE companies in the United States launched, which is publishing, multimedia and online image vector illustration software industry standard. With its powerful function, thoughtful user interface, it occupies most share of the vector editing software in the world. With incomplete statistics, 67\% of global designer in art design, especially with masturbator based on the use of ADOBE's patent - Postscript technology, illustrator has fully occupied professional print area. Whether line art designers and professional illustrator, graphics artist making multimedia, or Internet page, or the design of the online content producers, they will all find its powerful function and simple interface design style is unmatched by other similar software after using illustrator software. With the continuous development of network technology, the development direction of ADOBE is also constantly adjusted, many new functions such as illustrator10 has strengthened the position of it in the web design. 


\section{Photoshop}

As graphic image processing software, look from the function, Photoshop can be divided into the school image editing and image synthesis, color and special effects production part four aspects.

We know that whatever scanning figure file or digital cameras photographed image file all belongs to the type of image. Photoshop is a set of image processing software. [3]It can set more than one image file to combine, a few images through the layer operation, tools used for synthesis of complete and clear meaning communicated image the image synthesis, it is often use the set of methods and means of artistic design. Drawing tools provided by Photoshop can have a really good image and the creative fusion; make the image synthesis without clothing seamless, good visual effect.

In a word, there are so many various kinds of design software on the market, as a modern designer, he must have easily navigated this efficient software to carry on the design expression ability, and in the same type software to master at least one. In fact, the key to use relevant software design is design originality, because the master software can get started as long as the proper time, but the improvement of design ability needs long time of cultivation and influence. And at the same time, the software proficiency is just the sort of capacity. To be a real stylist, people should not only has skilled professional and technical ability, must also understand more knowledge, has the good professional accomplishment, can he make the design work has a real soul.

\section{Digital image visual identification system}

The continuous development of new media art leads to the development of the emerging digital visual design. Since the emergence of computer and network, the content of the digital visual design also increases, such as the emergence of new communication forms like Internet advertising, website design, digital display advertising, digital display design, which expands the scope of digital in art design, become the mainstream of the era of new media art. Especially in the field of graphic design, digital graphic design occupies a larger market.

\section{Visual identification system of corporate image}

Corporate image visual identification system is to use the comprehensive method of visual factors to set up the enterprise image. From the historical perspective, it has been for about one hundred years old for enterprises to use the trademarks and other marks to set up their own image. And trademark history of China is much older. Existing data prove that "white rabbit" brand scissors advertising in the northern song period of the includes all the basic elements of modern advertising like the enterprise and product trademark, advertising language, service guarantees, which is currently one of the earliest complete corporate image design. But these early activity is dispersed, no systematic, lack complete and scientific design rules and principles. Precipitated by economic development, the first important graphic designers in the United States laid the foundation of modern corporate image design; some large enterprises in Europe also entered the phase of corporate image design after the war. The concept of corporate image design has been introduced into Japan in the 1970s. The application and development of the Internet, finally forms a set of complete and scientific corporate image visual identification system.

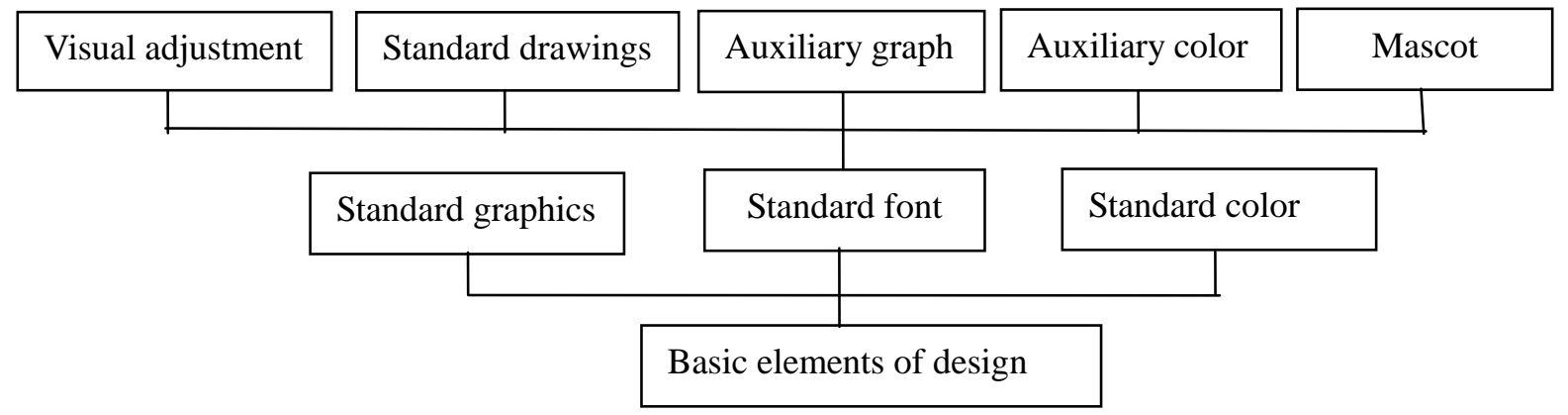

Figure2. Typical process for maintaining database 


\section{Digital image visual identification system}

Seen from the development of China's current situation, the development of new media technology and art makes our network system develop rapidly, especially in the development of computer network as the main body. This development brought a lot of advantages for our life, work, study, communication, but it also has had a great effect on traditional media. For example, information from newspapers, newspaper has lagged far behind in the efficiency of the network brings us; Correspondence is now behind the popularity of mobile networks, etc., all of which make the merchants and the business spread and pay attention to the new media, which attracts more usage of digital design arts. Various businesses also makes the corresponding relatively fresh digital design arts related promotion planning according to the characteristics of different new media.

Digital design art has already been classified as a single induction for the digital art class. Several of them at the same time give priority to new generation designer with painting life. [4]They specialized in digital design arts, with their own artistic accomplishment to digital design must study the hardware and software of the equipment. Look at this point can be sure that the size of the digital art design of the large, extensive content, the development of new media technology makes our new digital design category.

And corporate image visual identification system also faces such confusion. Firstly, our country's enterprise image visual identification system gradually decline caused and we need to develop for each enterprise development in our country new enterprise image visual identification system, which cannot blindly follow the experience of European countries, nor induct the Japanese again. So, enterprise image visual identification system suitable for the digital new media to promote should be created.

\section{Three-dimensional digital}

Pass class hierarchy principle: for complicated problem, decompose its features of wood elements, and then press the elements and attributes, subordinate relations between different levels, is controlled by layer elements. The top-down relationship can form a hierarchy. Top expresses the analysis standard; criterion and criterion layer is located in the middle, the lowest is decision scheme.

Pair wise comparison principle: based on the comparison between the two factors, clear the importance of each factor relative standards, on which basis constructing judgment matrix, then the approximate calculation relative importance of combination weight vector to conduct the consistency test to determine the weight distribution.

This principle can be showed bye formula.

Suppose the weighting factor of $\mathrm{n}$ scheme is $\mathrm{W}$ :

$W^{T}=\left[w_{1}, w_{2}, \ldots, w_{n}\right]$

Make mutual comparison with 1 to 9 marking between n scheme, we can get matrix A:

$A=\left(a_{i j}\right)$

$a_{i j}=w_{i} / w_{j}$

Then get:

$A W=n W$

When $\mathrm{A}$ is consistency matrix, eigenvalue $\mathrm{n}$, characteristic vector for $\mathrm{W}$ :

$A W=\lambda W$

$\lambda_{\text {max }} \geq n$

Positive and negative matrix:

$\lambda_{\text {max }}=n$

\section{Summary}

Corporate visual identity design is the most important carrier of the brand to spread enterprise culture. Choose the best means of communication is one important marketing strategy for enterprises to be bigger and stronger. The digital VI design is the enterprise requirements of 
information age. The design of the digital image recognition is a result of enterprise digital recognition mechanism, the necessity of modern enterprise development's adaptation to the digital age. It has a very profound significance no matter for system management policy-makers, designers or for application layer of the general staff.

\section{References}

[1] Liu Huifen. Digital media design [M], Beijing. Tsinghua university press, 2006(2): 9-22.

[2] Chenqing. VI design templates of Shaanxi people's fine arts publishing house, 2006(1):24.

[3] Zhang Dianyu Jing xiuping. Theory of tissue characterization of CIS design. Journal of north China water conservancy and hydropower college (social science Edition). 2001 (6): 26-32.

[4] Craig A. DcLarge. The role of the intranet is bread knowledge management. Design Management Journal, 2003 (14):61. 